\title{
Staff Absenteeism: The Case of Wa Municipal Education Office of the Ghana Education Service
}

\author{
Hafiz Bin Salih \\ Coordinator, Second Cycle Schools, Wa Municipal Education Office, Ghana Education Service, Wa, Ghana \\ Email: hafizbinsalih@yahoo.com
}

How to cite this paper: Salih, H.B. (2018) Staff Absenteeism: The Case of Wa Municipal Education Office of the Ghana Education Service. Open Journal of Social Sciences, 6, 1-14. https://doi.org/10.4236/jss.2018.68001

Received: July 9, 2018

Accepted: July 30, 2018

Published: August 2, 2018

Copyright (C) 2018 by author and Scientific Research Publishing Inc. This work is licensed under the Creative Commons Attribution International License (CC BY 4.0).

http://creativecommons.org/licenses/by/4.0/

(c) (i) Open Access

\begin{abstract}
Work absence is a critical practice in the world since the consistent presence of workers in the workplace is essential to attaining the aims of any department or institution. As a result, the management might fail to realize its targets. Thus, this paper will enlarge the understanding of the field by checking the matter at the Wa Municipal Education Office as the case analysis. Absenteeism impacts the general work productivity, and, consequently, can be thought of as the antithesis of output because productivity is zero through times of absence. Even though the consequence of personnel absenteeism on output is certain, some institutions might dismiss the need to assess their management procedures.
\end{abstract}

\section{Keywords}

Absenteeism, Staff, Management, Productivity, Strategies

\section{Introduction}

Work absence is a serious practice on the globe since consistent attendance of employees at the workplace is critical to accomplishing the goals of any institution or department. Scholars link employee absenteeism to backlogs, low productivity, and work delay [1]. This issue arises when workers fail to report to work as scheduled. Hence, it does not include individuals who do not appear on the job on approved days of absence or during suspensions, vacations, strikes, weekly rests, and holidays. Organisations tend to make adequate preparations for these forms of absence as a way of managing their potential negative impacts. Consequently, such absences provide immense benefits to the employee and the firm. It is worth mentioning that people who quit without informing their employers are considered absentees until the management officially removes them 
from the payroll.

Absenteeism can be classified based on the reasons that prompt employees to miss work. Absenteeism often occurs because of low commitment by the administration, illnesses, and dissatisfaction with the job [2]. However, failing to report to work because of family and health issues are usually unavoidable and abrupt. Hence, the management might not have measures of addressing the issue of staff adequacy during such circumstances. Scholars classify unscheduled absenteeism into involuntary and voluntary absenteeism [3]. The latter type of absenteeism arises when a worker fails to go to work due to an unsatisfactory reason, whereas the former one occurs when acceptable circumstances, such as diseases, prompt an individual to miss work. The classification of absenteeism into voluntary and involuntary allows administrations to choose the most acceptable measures to address the problem.

\section{Statement of the Problem}

Staff absenteeism is a major problem that affects many sectors of the economy. It leads to a considerable cost to any institution, even when the administration does not pay the absent employee [4]. The issue of staff absenteeism is impacting negatively on the activities of the Wa Municipal Education Office of the Ghana Education Service. This problem occurs since the work becomes disorganized and schedules are delayed. Consequently, the organization may fail to achieve its goals or meet its delivery dates. To exacerbate matters, sick pay significantly increases the cost of absenteeism. Hence, individuals, businesses, and state agencies should strive to minimize the occurrence and cost of staff absenteeism [5]. For instance, the provision of weekly rests and recuperation, suitable housing facilities, adequate compensations, and appropriate working conditions may play an important role in addressing this widespread problem. Hence, enhancing the workers' working and living conditions is critical.

There are no official statistics regarding the cost of staff absenteeism to Ghana's economy. However, findings from other parts of the planet may provide invaluable insight into the issue. For instance, the United Kingdom lost billions of dollars after employees in the country failed to report to work for a total of 137 million days in 2016 [6]. Besides, the issue cost businesses in the region an annual loss of one week per person. Likewise, high absenteeism in Wa Municipal Education Office adversely impacts the implementation and maintenance of its programs and functions.

Clearly, the Wa Municipal Education Office of the Ghana Education Service often finds it exceedingly challenging to reduce the degree of staff absenteeism, lower administrative costs, and increase employee productivity. However, this issue adversely affects the economic and social growth of a country [7]. Scholars maintain that employee absenteeism contributes to significant costs to the economy and businesses. Accordingly, the management of the Wa Municipal Education Office of the Ghana Education Service and other state agencies should 
strive to accomplish their strategic objectives and goals by implementing measures that effectively reduce the rate of absenteeism. Moreover, they must seek to address employees' needs to ensure that they support the vision and mission of the agency, department, or organization. Overall, managing staff absenteeism is a challenging task.

Staff absenteeism is indeed a challenging issue to the top management of the Wa Municipal Education Office of the Ghana Education Service.

\section{Background of the Study}

\subsection{Causes of Absenteeism}

Work absence, which can be involuntary or voluntary, arises from various issues. Research proves that absenteeism is a multifactorial phenomenon [8]. Researchers mainly attribute this problem to health-related issues [9]. For instance, there is a high probability that smokers, individuals with relatively high body weight, and people who rarely engage in physical exercises will report significantly high rates of absenteeism. Besides, researchers link work absence to demographic and organizational influences, job dissatisfaction, long working hours, poor leadership, and the lack of employee morale [10]. Therefore, while involuntary absenteeism mainly arises from health issues, voluntary absence might be influenced by a wider range of factors.

Most organisations find it problematic to address staff absenteeism because the management does not realize the complexity of factors causing the problem. Unfortunately, relatively few organizations conduct research to gain insight into the causes of work absences within their firms. Furthermore, most studies focusing on the subject examine the issue of voluntary absence and the health condition of workers. Nonetheless, Nicholson's theory of attachment demonstrates that other factors, such as a person's maturity and age, contribute to staff absenteeism [11]. The model suggests that young people report a significantly high frequency of short-term work absence. Conversely, aged individuals tend to miss work for relatively long spells. Besides, family responsibilities, minor and serious health conditions, work-related accidents, long working hours, absences considered an entitlement, drug use, and personal challenges are some of the key causes of employee absenteeism. Furthermore, mental or emotional strain related to the workplace, leisure accidents, reduced morale, unauthorised holiday, and the lack of dedication contribute to the issue of non-attendance of a person at work. Hence, firms that report staff absenteeism should strive to address these problems.

\subsubsection{Minor Illnesses}

The mental and physical wellbeing of an individual is an important determinant of his or her health status. Indeed, poor mental and physical wellbeing are key contributors to a high absence rate. Interestingly, many studies focusing on work absences do not consider the impact of these critical factors on absenteeism. Scholars often ignore the health of an employee as a cause of absenteeism since 
diseases are categorized in the "involuntary" absence group. However, it is worth remembering that most organizations suffer from the issue of 'short-term' absences arising from minor illnesses. Consequently, it is important to consider minor illness an important variable while conducting research on this subject.

Usually, individuals who miss work because of self-limiting conditions such as minor illnesses are healthy enough to attend to their duties at the workplace. This observation is consistent with the A-B continuum, which is reported in Nicholson's attachment theory [12]. This model suggests that minor health issues would be positioned at the " $\mathrm{A}$ " level of the A-B continuum in case a person offers his or her services in a highly demanding work setting. Conversely, minor ailments would fall at the " $\mathrm{B}$ " side of the $\mathrm{A}-\mathrm{B}$ continuum if an individual is healthy and works in a less demanding workplace. Hence, a worker whose condition falls at the "B" end of the continuum "could have" gone to work.

\subsubsection{Stress}

Mental or emotional strain refers to people's response to the challenge of balancing certain demands based on their capacity to meet them. Stress is amongst the most reported causes of long-term staff absenteeism. This issue eventually causes ill health. American College of Cardiology [13] maintains that stress is a negative feeling that leads to dry mouth, shortness of breath, increase in pulse rate, and other physical symptoms. However, it affects each employee differently; in fact, some workers experience significantly more symptoms compared to their colleagues. Occupational stress is a person's view of the demands of the workplace and his or her ability to perform those responsibilities.

Stress affects many individuals and organisations. However, the management of many organisations lacks knowledge of the way to address it [14]. Unfortunately, the current literature presents contradictory findings regarding workplace stress. For instance, some scholars assert that males are more prone to mental or emotional strain, while other investigators maintain there is a high prevalence of stress among females. Consequently, scholars find it exceedingly challenging to predict the trends that will emerge from stress.

Most people only consider the negative impacts of stress on an employee. However, researchers state that stress also has positive effects on workers based on the extent of the agent that causes the strain. Previous research on the relationship between stress and work absences usually assesses the impact of the emotional strain based on the "acute stress response" ("Flight or Fight" response) [15]. This coping mechanism suggests that a person will either "fight" these workplace demands or choose to "flee". According to [15], an employee with a limited degree of stress may enhance his or her performance. However, an "unacceptable" level of stress can reduce the individual's efficiency. Besides, the strain can affect the person's initiative and performance and make the employer unconcerned with the welfare of other people in the organisation. This problem occurs when the management allows the subordinates, particularly those engaging in a demanding role, little control over the management and performance of 
the job. The issue is compounded by unsafe working conditions or lack of say in the organisation. Hence, stress can play an important role in the daily activities of a worker, but an intense level of the strain may adversely impact the employee's operations.

Many organisations have not implemented effective measures to prevent workplace stress. In the meantime, [15] assert that there is a steady rise in the prevalence of stress among employees. It is important to notice that many organisations have comprehensive knowledge of the adverse health impacts of stress. However, most of them do not implement procedures and policies to address this issue. In fact, many institutions tend to tackle the problem after facing a serious trigger, such as a reduction in productivity, a rise in the frequency of absenteeism, the enactment of related regulations, or an increase in operational costs. In order to avoid such adverse effects, organisations should strive to address these problems early enough.

An organisation can employ a three-step mechanism to manage the problem of staff absenteeism arising from stress. Firstly, employers should assess the factors that are responsible for workplace stress. They can accomplish this goal by reviewing the set procedures and policies. Secondly, the management should engage every member of staff in stress management practices to lower the level of employees' stress. It should consistently assess the workers' condition. Lastly, the administration ought to evaluate the progress of the implemented programs and processes and make relevant adjustments regularly. This strategy plays an important role in enhancing future implementations of the appropriate programs and stress management measures. Nevertheless, businesses must set realistic objectives. Hence, firms should develop strict policies to curb the growing concern of work absences.

\section{Work-Life Balance (WLB) and Staff Absenteeism}

Work-life balance focuses on the extent to which employees achieve equal degrees of satisfaction and engagement in their personal and social life and work performance. This factor has a considerable impact on the performance of people. In particular, individuals who have the capacity to split their time between their careers and other aspects of life tend to perform better than their colleagues. A person with a healthy work-life balance assigns a priority to his or her community duties, household, and work. However, it is exceedingly challenging for many people to effectively perform these responsibilities. [16] maintains that concentrating on the efficient management of job and other personal matters is an important aspect of WLB. Accordingly, members of the society who have the capacity to balance their work-life invest their time and energy to both domains.

An increase in the workload of a worker adversely affects the person's WLB. Indeed, people view WLB as the assessment of a worker's capacity to manage the work, family, and personal responsibilities effectively. However, "balance" is a 
subjective assessment that differs according to people's views. For instance, a person may gain satisfaction from spending more time in the workplace, while another can appreciate having more time at home. Nonetheless, many scholars concur that relatively long working hours tend to cause family-work conflict, which contributes to staff absenteeism [17]. Hence, it is important to assess the extent of working that adversely impacts the work-life balance among employees at Wa Municipal Education Office.

\section{Purpose of the Study}

The purpose of this study is to assess the causes and effects of staff absenteeism at the Wa Municipal Education Office of the Ghana Education Service. Consequently, it will help in understanding the effects of work absence on routine work. The findings will enlighten human resource managers on the extent of employee absenteeism and the measures of reducing its prevalence. In his article, [18] asserts that scholars ought to conduct comprehensive research on this subject. Thus, this paper will expand the knowledge of this field by assessing the issue at the Wa Municipal Education Office of the Ghana Education Service as the case study. The public sector deserves an ample analysis since it offers unique services to the society. For this reason, the paper will examine the relationship between workplace absenteeism and service delivery. It is worth mentioning that scholars have not chosen this place while completing their research. Hence, this study will provide invaluable insight into the ways of addressing absenteeism in other municipal education offices in Ghana since they employ a similar structure. Furthermore, the study will suggest measures for addressing the problem. The findings may help in enhancing employee productivity and reducing workplace absenteeism.

\section{Significance of the Study}

The negative impacts of absenteeism determine the importance of addressing this problem. Work absences negatively impact business growth, productivity, and operations [19]. The significance of the study is to assess the causes and effects of staff absenteeism at the Wa Municipal Education Office of the Ghana Education Service to make informed recommendations to help solve the problem of staff absenteeism. The study provides an in-depth assessment of the causes and effects of staff absenteeism at the Wa Municipal Education Office of the Ghana Education Service. It also examines the structures upon which the Wa Municipal Education Office of the Ghana Education Service has been built and the worldview upon which staff absenteeism is founded.

The assessment has revealed how the management of the Wa Municipal Education Office of the Ghana Education Service feels about dealing with the problem of staff absenteeism that seems intractable. The findings will, therefore, not only be adding to existing knowledge on how to deal with staff absenteeism, but also provide a pathway for dealing with similar issues elsewhere in the country 
and the world at large.

Researchers assert that workplace absenteeism is a major cause of direct and indirect costs [19]. Hence, this study is of relevance to Government, Educational administrators, Non-Governmental Organizations, the General Public and other stakeholders who are concerned with the sustenance and development of formal education in society. It is hoped that such stakeholders would take a keen interest in working together to bring about progress and development in state agencies and other agencies with similar backgrounds. Although literature abounds on employee absenteeism, that of staff absenteeism in state-owned educational institutions in Ghana is scanty if not virtually non-existent. The findings of this study are documented to prevent the assessment of the causes and effects of staff absenteeism at the Wa Municipal Education Office of the Ghana Education Service from disappearing into oblivion.

This would also serve as a source of historical knowledge for the staff of the Wa Municipal Education Office of the Ghana Education Service. In fact, lost work-time makes it challenging for employers to achieve the objective of an organisation and attain high productivity levels [1]. In this way, the study also represents an opportunity to reflect on the lessons gathered from the experiences of the staff of the Wa Municipal Education Office of the Ghana Education Service. Consequently, this study sought to explore beyond the already existing problems so as to unearth new insights and contribute to the existing body of knowledge in the area of educational leadership and administration.

\section{Research Methodology}

Research methodology is an essential element of research because it details the steps taken in conducting a study. The latter facilitates and positively influences the discipline being studied. The paradigm, approach, and method are examined. The rationale behind the appropriate choice of procedures and processes that were applied to achieve the study objectives is therefore explained.

\subsection{Target Population}

As of June 2018, the study population consisted of 68 staff of the Wa Municipal Education Office of the Ghana Education Service (48 male and 20 female). The age range of the staff was between 38 years and 60 years. Also, the work experience of the staff was between 15 years to 35 years of work experience. The sample size was 37 staff ( 27 male and 10 female). Four of the participants were the heads of their respective departments, namely the Finance and Administration Department, Human Resource Department, Planning Department and Supervision Department. While all the 7 management members were purposively sampled, the other participants were selected through simple random sampling. Participants were both management and staff. Management of the Wa Municipal Education Office of the Ghana Education Service is made up of the Municipal Director of Education, the four Frontline Deputy Directors and some senior officials at the Municipal office. The researcher used semi-structured interviews 
and a questionnaire to collect data. The researcher also made use of the information from the staff attendance register.

\subsection{Data Analysis}

Data analysis involves the preparation and organisation of data into meaningful groups, including the search for conceivable patterns and existing relationships. All item responses were analysed. Data analysis was done based on these research questions:

1) What causes employee absences in the workplaces?

2) What are management's assessments of staff absences?

3) Are the existing practices for managing absences effective?

4) What are the best measures to address staff absenteeism?

\section{Research Results}

\subsection{Causes of Employee Absences in the Workplaces}

When the staff was asked to indicate the reasons behind their last absence from work, $64 \%$ of them noted non-illness related causes. Absenteeism that was illness-related consisted of physical and mental illnesses. Non-illness reasons included personal issues, family issues, stress, practical issues, looking for another job, and job dissatisfaction. Issues such as child naming ceremony, funeral occasion and attendance at religious as well as traditional festivals are the main causes of non-illness absenteeism of the staff of the Wa Municipal Education Office of the Ghana Education service. Sickness and stress were also mentioned as causes of staff absenteeism.

\subsection{Management Assessments on Staff Absences}

The majority of management considered absenteeism as costly and negatively affecting the productivity of the organisation. However, only about half of the total management indicated absenteeism as a serious concern in the workplace while less than half of staff considered an absence as an issue of concern for the Wa Municipal Education Office of the Ghana Education Service. It was therefore revealed that the problem of staff absenteeism was of grave concern to both management and staff of the Wa Municipal Education office of the Ghana Education Service. The study found that $87 \%$ of management agreed that absenteeism is costly for the organisation (Figure 1).

The $83 \%$ of management agreed that absenteeism negatively affects output (Figure 2). Moreover, 53\% of management noted absenteeism as a serious concern in the workplace (Figure 3 ). Besides, $44 \%$ of staff considered absenteeism as a serious issue in the workplace (Figure 4).

\subsection{The Effectiveness of the Existing Absence Management Practices}

Staff usually provides medical notes from physicians. However, only $8 \%$ of staff consider it as an adequate absenteeism management practice. It was revealed 


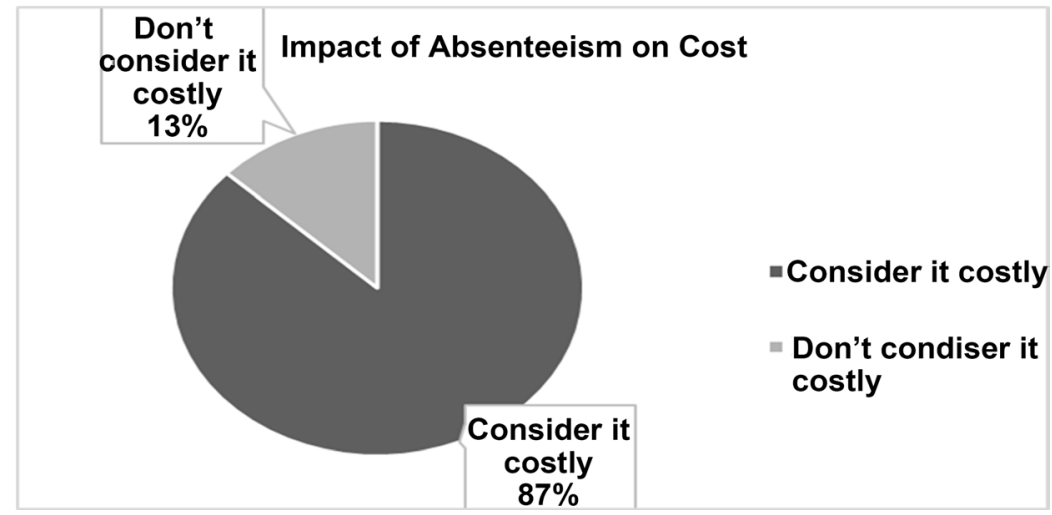

Figure 1. Management consideration on whether absenteeism is costly.

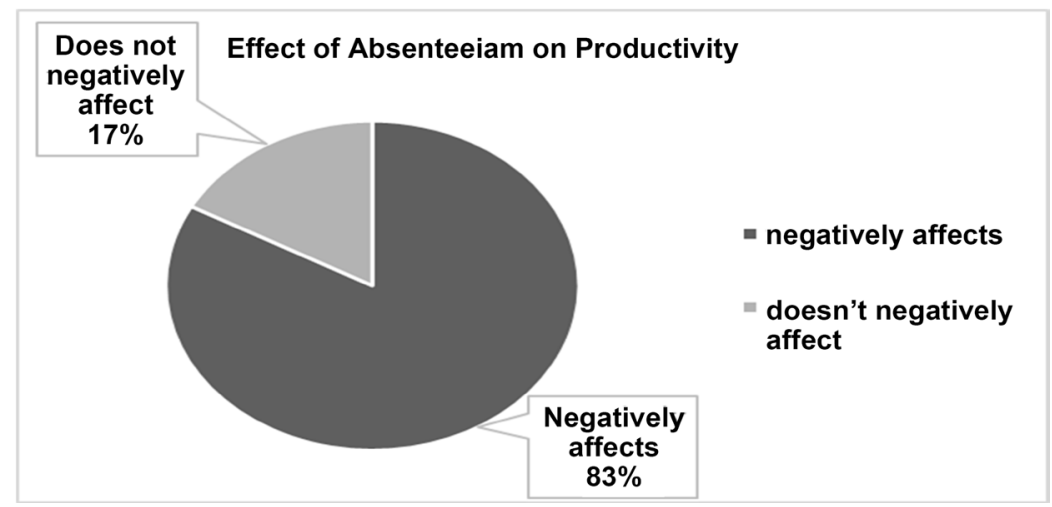

Figure 2. Management's deduction on the effects of absenteeism on production.

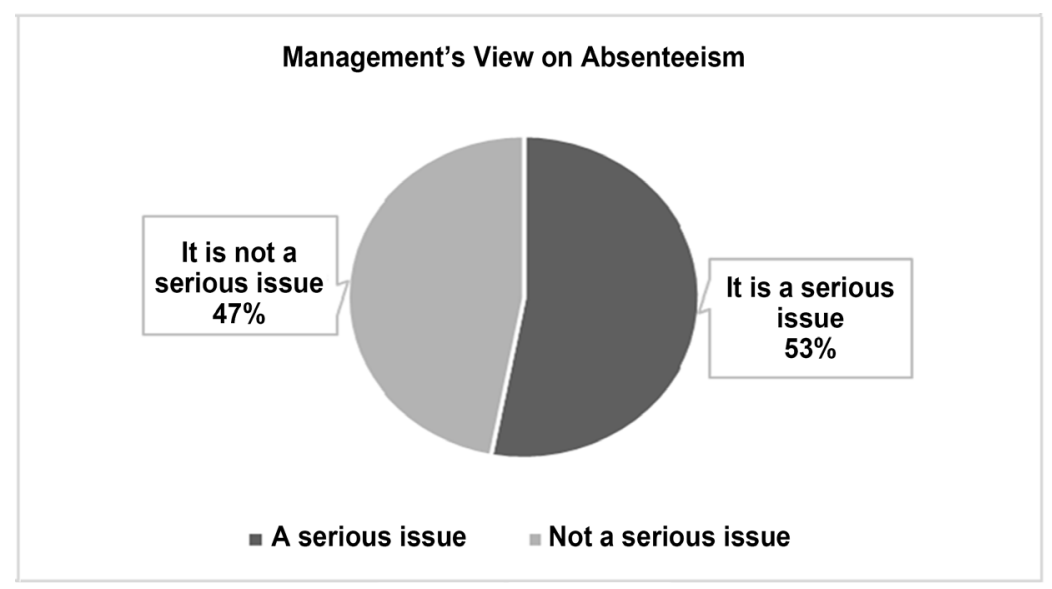

Figure 3. Management's conclusion about absenteeism in their workplace.

that the existing practice of asking staff to submit a physician note before being granted permission to go on sick leave is not an effective mechanism for granting sick leave to staff. Also, the staff attendance book is not closely supervised by management hence its existence is not of relevance in curbing staff absenteeism at the Wa Municipal Education office of the Ghana Education Service.

Management generally understands that health and stress issues contribute to absenteeism, and $87 \%$ noted that (Figure 5). Probably a factor, $44 \%$ of employees 


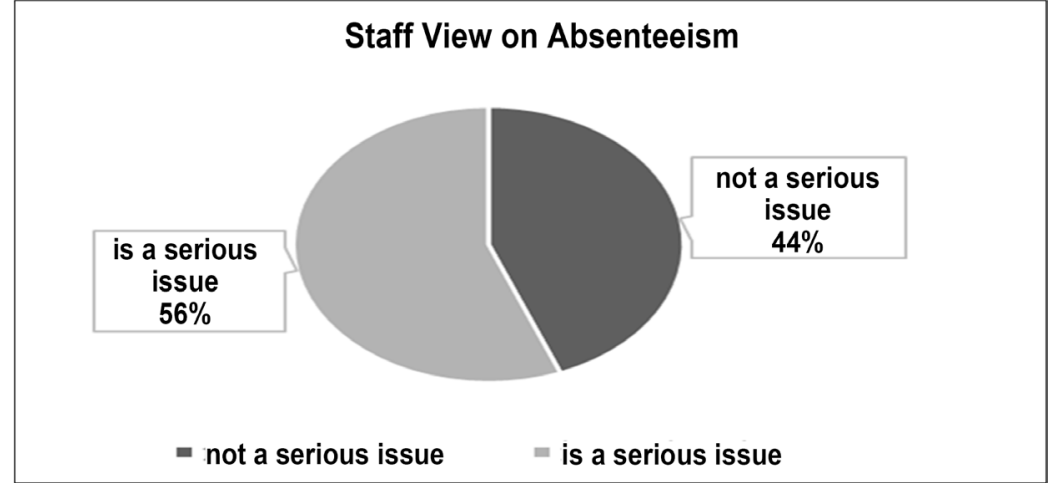

Figure 4. Staff's conclusion about absenteeism in the workplace.

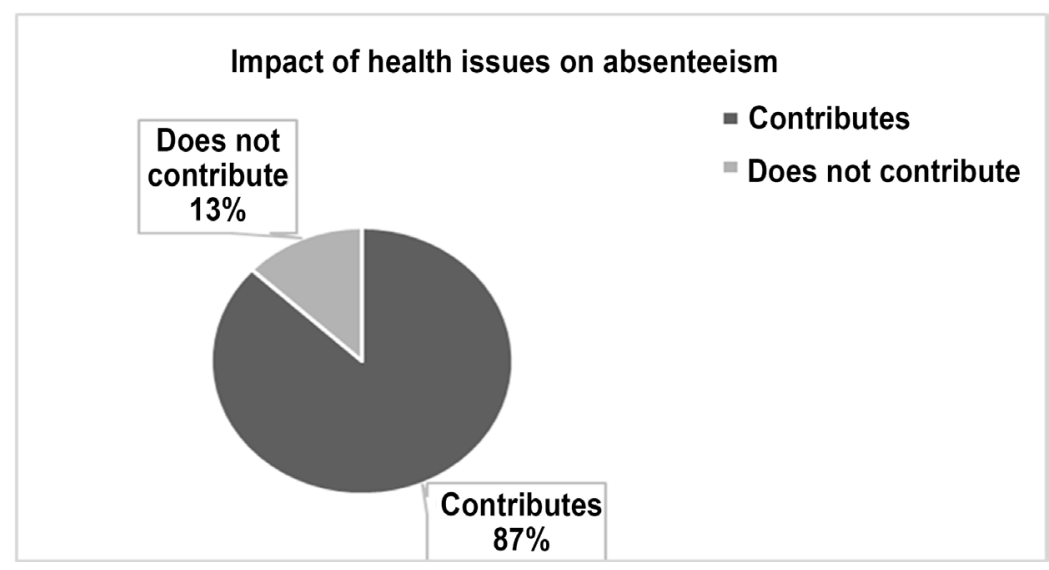

Figure 5. Staff s conclusion on whether health and stress issues contribute to absenteeism.

stated that organisations do not create a wellness-supported environment at workplaces (Figure 6).

The findings revealed that strategies should be implemented to ensure improvement in managing the problem of staff absenteeism at the Wa Municipal Education Office of the Ghana Education Service. Management should ensure staff receives enough rest periods for the reduction of fatigue. Also, staff should consider unauthorised absence as an issue of utmost significance, so as not to compromise the level of commitment required to control absenteeism. Furthermore, clear and sound workplace policies should manage absenteeism, including fair and adequate discipline, which is designed to deter employees and promote a culture committed to lessening absenteeism.

The findings further revealed that the management of the Wa Municipal Education office of the Ghana Education Service should ensure that sick leave regulations and the process of presenting medical notes should be well defined to eliminate confusion on the necessary actions when needed. Additionally, employees should be counseled as a precondition to disciplinary action. Consistent disciplinary measures should be implemented. Moreover, habitual offenders should face appropriate disciplinary consequences henceforth. Meanwhile, 


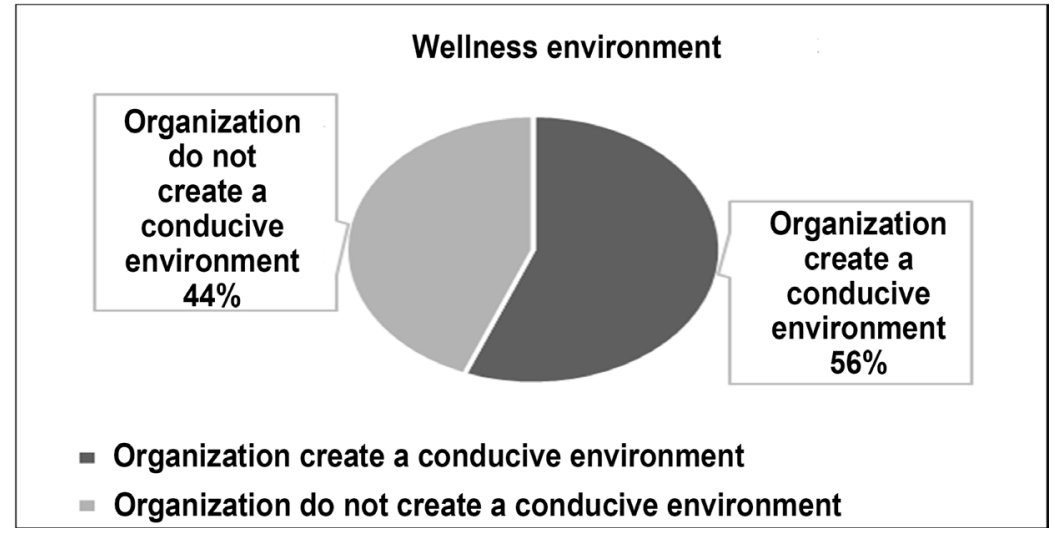

Figure 6. The staff's argument on whether the organisation creates a conducive working environment.

management should also formulate procedures for investigating absences that the staff cannot control. Past employee records should be consulted before determining the appropriate course of action. Hence, management should not only track and measure absenteeism to promote attendance, but also should discuss it with the employees turning it into a team effort.

\section{Conclusions}

Staffs of the Wa Municipal Education Office of the Ghana Education service who are of the habit of absenting themselves from work do that based on non-illness issues. The main causes of staff absenteeism relates to issues such as child naming ceremony, funeral occasion and attendance at religious as well as traditional festivals.

Staff absenteeism at the Wa Municipal Education Office of the Ghana Education Service affects the overall work productivity, and, thus, can be regarded as the antithesis of output since productivity is zero during periods of absence. Although the implication of staff absenteeism on output is inevitable, some institutions may ignore the need to review their management practices.

It is instructive to note that measures put in place to curb staff absenteeism at the Wa Municipal Education Office of the Ghana Education Service are not effective.

\section{Recommendations}

Management should isolate predominant causes of absenteeism, identifying legitimate incidences, regular offenders, and illegitimate absences enable it to employ sufficient measures targeting specific factors. Effective policies should be implemented with the management ensuring that all employees completely understand such systems. Moreover, the possible repercussions that may follow for failing to adhere to such policies should be well outlined and explained.

Furthermore, a committee should be made to engage the staff in addressing all aspects surrounding absenteeism regularly. To ensure that disciplinary records 
and attendance are updated, a timely action should be a priority, enabling management to make appropriate decisions according to each case of absenteeism. Attendance incentives should be applied for employees to associate positively for regularly reporting for duty.

\section{Definitions}

- Staff absenteeism: Unscheduled absence of a person from his or her place of work.

- Productivity: The deliberate conversion of labour, capital, and other input resources into the required outputs.

- Strategies: The assessment and directing of the much-needed resources to accomplish a specific objective or address a critical issue.

- Voluntary absenteeism: The decision of a person to avoid reporting to work due to unsatisfactory reasons [3].

\section{Limitations of the Study}

Factors that are beyond the scope of the person conducting a study may impact the research. For instance, the paper focuses on the Wa Municipal Education Office of the Ghana Education Service, which constitutes a major limitation. Scholars argue that a small sample makes it exceedingly difficult to generalise study outcomes and conclusions to similar settings and situations. In fact, the research will include the responses of a few employees due to time constraints. The short time span will make it extremely challenging to interview all respondents and gather the much-needed information. Similarly, the process of answering all the questions that will be included in the questionnaire may require much time, particularly if the respondents do not understand the key terms and concepts. Besides, the limited scope of information regarding the causes and impacts of absenteeism may affect the findings. Indeed, having a keen interest in factors that the management of Wa Municipal Education Office can control may negatively impact data collection. This issue may occur since other factors that are beyond the scope of the administrators can reduce productivity and the rate of absenteeism. Importantly, the subjects may fail to express their views on the topic frankly, which is likely to contribute to response bias. Hence, a number of factors associated with the scope of the study and the target audience may adversely impact the research findings.

\section{Conflicts of Interest}

The authors declare no conflicts of interest regarding the publication of this paper.

\section{References}

[1] Mullen, K.J. and Rennane, S. (2017) Worker Absenteeism and Employment Outcomes: A Literature Review. National Bureau of Economic Research. http://www.nber.org/aging/drc/papers/odrc17-20.pdf 
[2] Vishwakarma, R.K., Shukla, A. and Nougriaya, S. (2015) Job Satisfaction and Its Impact on Absenteeism: A Case Study Related to Teachers in Private Engineering Colleges. International Journal of Engineering Technology \& Management Research, 3, 10-15.

[3] Belita, A., Mbindyo, P. and English, M. (2013) Absenteeism amongst Health Workers-Developing a Typology to Support Empiric Work in Low-Income Countries and Characterising Reported Associations. Human Resources for Health, 11, 34. https://doi.org/10.1186/1478-4491-11-34

[4] Kocakülâh, M.C., Bryan, T.G. and Lynch, S. (2018) Effects of Absenteeism on Company Productivity, Efficiency, and Profitability. Business and Economic Research, 8, 115-135. https://doi.org/10.5296/ber.v8i1.12395

[5] Isah, E.C., Omorogbe, V.E., Orji, O. and Oyovwe, L. (2008) Self-Reported Absenteeism among Hospital Workers in Benin City, Nigeria. Ghana Medical Journal, 42, $2-7$.

[6] Comer, M. (2017) Sickness Absence in the Labour Market: 2016. Office of National Statistics.

https://www.ons.gov.uk/employmentandlabourmarket/peopleinwork/labourproduc tivity/articles/sicknessabsenceinthelabourmarket/20162

[7] Bargas, E.B. and Monteiro, M.I. (2014) Factors Related to Absenteeism Due to Sickness in Nursing Workers. Acta Paulista de Enfermagem, 27, 533-538. https://doi.org/10.1590/1982-0194201400087

[8] Slany, C., Schütte, S., Chastang, J., Parent-Thirion, A., Vermeylen, G. and Niedhammer, I. (2014) Psychosocial Work Factors and Long Sickness Absence in Europe. International Journal of Occupational and Environmental Health, 20, 16-25. https://doi.org/10.1179/2049396713Y.0000000048

[9] Frick, B.J., Goetzen, U. and Simmons, R. (2013) The Hidden Costs of High-Performance Work Practices: Evidence from a Large German Steel Company. Industrial and Labor Relations Review, 66, 198-224. https://doi.org/10.1177/001979391306600108

[10] Herrmann, M.A. and Rockoff, J.E. (2011) Worker Absence and Productivity: Evidence from Teaching. Columbia University. https://www0.gsb.columbia.edu/faculty/jrockoff/papers/herrmann_rockoff_teachin g_disruptions_aug_2011.pdf

[11] Leiter, M.P., Day, A. and Price, L. (2015) Attachment Styles at Work: Measurement, Collegial Relationships, and Burnout. Burnout Research, 2, 25-35. https://doi.org/10.1016/j.burn.2015.02.003

[12] Egan, G. (2011) An Investigation into the Causes of Absenteeism in "Company X". National College of Ireland. http://trap.ncirl.ie/590/1/Thesis_-_Geraldine_Egan_-_22_Aug_2011.pdf

[13] American College of Cardiology (n.d.) Breathing Problems: How to Control Stress. https://www.cardiosmart.org/ /media/Documents/Fact\%20Sheets/en/zp3796.ashx

[14] Roberts, R.K. and Grubb, P.L. (2014) The Consequences of Nursing Stress and Need for Integrated Solutions. Rehabilitation Nursing, 39, 62-69. https://doi.org/10.1002/rnj.97

[15] Broman-Fulks, J.J. and Kelso, K. (2012) Stress Management. ResearchGate. https://www.researchgate.net/profile/Joshua_Broman-Fulks/publication/273946086 _Stress_Management/links/5510d20f0cf20352196ca48c/Stress-Management.pdf

[16] Noor, K.M. (2011) Work-Life Balance and Intention to Leave among Academics in 
Malaysian Public Higher Education Institutions. International Journal of Business and Social Science, 2, 240-248.

[17] Razak, M.I., Yusof, N.M., Azidin, R.A., Latif, M. and Ismail, I. (2014) The Impact of Work Stress towards Work Life Balance in Malaysia. International Journal of Economics, Commerce and Management, II, 1-16.

[18] Reuben, M.B. (2017) A Critical Risk Analysis of Absenteeism in the Workplace. Journal of International Business Research and Marketing, 2, 32-36. https://doi.org/10.18775/jibrm.1849-8558.2015.26.3004

[19] Randhawa, N. (2017) Employee Absenteeism-Indian Industry Perspective. Imperial Journal of Interdisciplinary Research, 3, 35-42. 